\title{
Risk analysis and crisis response
}

\author{
Cengiz Kahraman
}

Published online: 22 April 2008

(C) Springer-Verlag 2008

Today's society is a risk society, filled with challenges as well as opportunities. Frightened by catastrophic events, such as 9.11, SARS, Indian Ocean earthquake and tsunami, South Asia earthquake disaster, and bird flu, people increasingly regard risk and crisis as urgent issues. The term risk analysis has different interpretations among various environments. However, there is a growing acceptance that risk analysis involves the development of the probability distribution for the measure of effectiveness. Furthermore, the risk associated is generally either given as the probability of an unfavorable value for the measure of effectiveness or measured by the variance of measure of effectiveness.

This special issue is devoted for the papers presented at the First International Conference on Risk Analysis and Crisis Response September 25-26, 2007, Shanghai, China. About 200 papers were presented at this conference and the extended papers of all were submitted after the conference for possible publication in this special issue of Stochastic Environmental Research and Risk Assessment. After a peer review using at least two referees for each paper, 12 papers included by this issue have been accepted.

The financial supply chain is increasingly recognized as an area offering significant potential for generating bottomline improvements and creating competitive advantage. In the first paper, considering the stability of the financial supply chain, the coordination evaluation and fuzzy multiobjective evaluation model of insurers' risk management are firstly studied by using large system theory and methods. The corresponding coordination evaluation index model

\section{Kahraman $(\square)$}

Department of Industrial Engineering,

Istanbul Technical University,

34367 Macka Istanbul, Turkey

e-mail: kahramanc@itu.edu.tr is then established to evaluate, forecast and control the actuality and the future of risk coordination management, and to improve the durative development for a combination pension model. The evaluation standards of numerous insurers are established to constitute a set of vectors. By presenting a dimensional point to each insurer, the optimal or the worst insurer is decided. Finally, the distances of each insurer to the optimal or the worst insurer on the basis of the Euclidean distance are counted, and the insurers' ordering according to the value of distances is sorted out.

The second paper presents the morphogenetic system which projects the output samples of fuzzy set to the input samples of the fuzzy sets. In the projection operator the author computes the best rules for the inferential or reasoning process. Modern uncertainty theories (fuzzy logic, Information diffusion) provide a calculus to obtain relationship by observation pattern. With the relationship obtained, the risk in different situation can be estimated. It is known that information structure is essential to forecast the future risk in different situations; the main difficulty in the forecast the risk is to extract rules from a non-coherent set of data. Fuzzy sets and fuzzy rules are essential to detect the uncertainty but are not sufficient to define in an optimal way the rules that describe the relationship among fuzzy variables.

Fire is a major risk in the event of large stadium due to fire coincidence with smoke flow and evacuation path. In the next paper, as a part of an effort to improve the life safety in large stadium, the simulation technology combined with fire spread and evacuation is developed. Besides that, in order to decrease the rate of people death in the large stadium fire, the interface between fire and the evacuation people must be designed in the simulation model, based on the influence laws to human behavior by smoke temperature, $\mathrm{CO}$ concentration and extinction coefficient in fire condition. Therefore, the investigation of effect of fire spread on life safety is needed. 
The dynamic changes of walking speed, route choice and mental state are obtained from automatic reading of fire data during the simulation of evacuation. The effect abruptly changes due to time-varying fire smoke parameters, especially local jamming and uneven efficiency of routes.

In the fourth paper, the authors show that explicit treatment of risks and uncertainties in agricultural production planning may considerably alter strategies for achieving robust outcomes with regard to environmental impacts and economic efficiency of spatial production patterns. They discuss production planning models under uncertainties and risks that may assist in planning locationspecific production expansion within environmental and health risk indicators and constraints.

Water pollution affects drinking water, rivers, lakes and oceans all over the world. This consequently harms human health and the natural environment. Water pollution can also affect the crops. So, water pollution is an important issue for humanity. Therefore, the control of irrigation water is a necessity. In the fifth paper, a methodology based on process capability indices (PCIs) is presented to control the levels of $\mathrm{pH}$, dissolved oxygen (DO) and temperature $(T)$ in dam's water for irrigation. fuzzy process capability indices (FPCIs) are proposed for this aim. The fuzzy estimates of $\hat{C}_{p}$ and $\hat{C}_{p k}$ are obtained for $\mathrm{pH}, \mathrm{DO}$, and $T$ based on Buckley's (2005) interval estimation approach and fuzzy specification limits.

The next study presents a methodology for risk analysis and assessment of grassland fire disaster, taking western Jilin province as a case study area based on GIS (Geographic Information System). Grassland fire disaster occurs frequently and infected livestock agriculture and social-economic development deeply in the grassland regions of Jilin province, China. Moreover, both the frequency of grassland fire and loss from them are considered to be increasing with the global warming and economic development. The natural disaster risk index (NDRI) method, analytic hierarchy process (AHP) and weighted comprehensive method are employed to make a grassland fire disaster risk index (GFDRI).

In the seventh paper, the author suggests a new definition of risk. He extends the concept of integrated risk assessment to include "integrated risk" assessment, where the integrated risk is considered as a synthetic phenomenon, which leads up to a new risk categorization. The basic principle to assess integrated risks is to identify risk sources, construct the relationship between the risk sources and adverse incidents and infer the possibility values the occurrence of adverse incidents, by risk source experts, system analysts and integrated risk analysts, respectively.

The crisis response system helps city managers implement a well-developed crisis management strategy that enables city managers to plan for, recognize, respond to, and recover from unexpected events, ranging from cyber attacks to natural disasters. Crisis response system is a tremendous and complex system. The perfect crisis response system is difficult to be designed. The system must integrate the information resources of emergency response units of the city. In the eighth paper, on the view of the value chain analytic in business management, the factors that affect the operational efficiency and running cost of crisis response system are analyzed.

The ninth paper proposes the application of an Artificial Neural Network (ANN) approach as a fast alternative to computational fluid dynamics models to simulate the behavior of a compartment fire. A novel ANN model named GRNNFA is specially developed for fire studies. It is a hybrid ANN model that combines the general regression neural network and fuzzy ART.

The next paper suggests a new approach to estimating the risk with uncertainties in phases, where the high uncertainty in a phase is to induce a high risk. The assumption of this approach is that a financial enterprise is able to control its action to avoid operational risk.

Emergency management evaluation as one of the important parts of ERM aims assessing and improving social preparedness and organizational ability in identifying, analyzing, and treating emergency risks. The eleventh paper first develops an emergency management evaluation model. It then proposes an extended fuzzy multi-criteria group evaluation method, which can deal with both subjective and objective criteria under multi-levels by a group of evaluators, for emergency management evaluation. A fuzzy multi-criteria group decision support system is developed to implement the proposed method for the case of emergency operating center/system evaluation.

Air pollution is one of the most important threats for the humanity. It can damage not only human health but also Earth's ecosystem. Because of the harmful effects of air pollution, it should be controlled very carefully. To do the risk assessment of air pollution in Istanbul, the process capability indices (PCIs), which are very effective statistics to summarize the performance of process are used in the last paper. Fuzzy PCIs are used to determine the levels of the air pollutants which are measured in different nine stations in Istanbul. Robust PCIs (RPCIs) are used when air pollutants have correlation. Fuzzy set theory is applied for both PCIs and RPCIs to have more sensitive results. More flexible PCIs obtained by using fuzzy specification limits and fuzzy standard deviation are used to evaluate the air pollution's level of Istanbul.

I hope that this special issue will serve as a useful source of ideas, techniques, and methods for further research in risk analysis and crisis response. I am grateful to the referees whose valuable and highly appreciated works contributed to the selection of the high quality papers published in this special issue. My sincere thanks go to Professor George Christakos, the editor-in-chief who was highly instrumental in bringing this project to its fruitful completion. 